\title{
Associativismo, profissões e identidade
}

\author{
Maria da Gloria Bonelli \\ Doutora em Sociologia (Unicamp) \\ Professora na Universidade Federal de São Carlos \\ gbonelli@uol.com.br \\ Jordão Horta Nunes \\ Doutor em Sociologia (Universidade de São Paulo) \\ Professor na Universidade Federal de Goiás \\ jordao@cienciassociais.ufg.br
}

E STE DOSSIE ENFOCA PRIMEIRAMENTE ARTIGOS sobre estratégias associativas, subsidiadas ou não pelo poder público, supostamente alternativas a um mercado de trabalho excludente, especialmente diante de limitações na qualificação. Várias temáticas e perspectivas de análise estão presentes, destacando a tensão entre os interesses e motivações nas experiências associativas e as diretrizes político-ideológicas que norteiam as políticas públicas, pois o princípio originário das associações e cooperativas no mundo do trabalho é a autogestão. Destaca-se também o processo de construção da identidade por trabalhadores(as) em ocupações e profissões nas áreas de produção ou serviços, influenciadas pelas formas de atribuição institucional, interação e organização do trabalho, mas também por fatores externos à experiência laboral, como arranjos de gênero na esfera doméstica ou no contexto cultural, além de motivações político-ideológicas. No caso das profissões que valorizam a centralidade da expertise na sociedade do conhecimento, os desafios surgem dos leigos, dos empreendedores, da lógica administrativa, do controle do Estado. As disputas entre esses ideários repercutem nas identidades profissionais, nas formas de se lidar com a semelhança e a diferença nos grupos ocupacionais e nas carreiras. Assim, a identidade no trabalho constitui, ao lado das análises da organização, da divisão social, da cultura e das representações do trabalho, um frutífero repertório para a pesquisa de profissões, onde prevalece um reconhecimento positivo do self, mas também de ocupações de baixa qualificação, empreendimentos associativistas ou experiências de trabalho atípico, em que a emancipação e o resgate intersubjetivo do trabalhador permanecem no horizonte.

O trabalho cooperado, de forma autogestionária ou alternativa, orientado por políticas públicas, movimentos sociais, ou até por motivações empreendedoristas não desvinculadas da lógica capitalista, constitui o tema principal em quatro artigos. Jussara Carneiro Costa, em Mulheres e Economia Solidária: Hora de Discutir a Relação!, analisa a participação feminina em empreendimentos e iniciativas no contexto da economia solidária, esta considerada prática distinta, em vários aspectos, do cooperativismo tradicional e alternativa ao modelo de produção capitalista. A autora analisa criticamente as reconstruções sobre as origens históricas da economia solidária, que ignoram ou desvalorizam o papel da mulher fora das ocupações fabris ou industriais. Incorporando elementos da argumentação de feministas como Joan Scott (1991), que enfatizaram a subsistência da divisão sexual de trabalho e da dominação e de estratégias de gênero masculinas em empreendimentos cooperativos alicerçados num discurso contestatório à lógica capitalista, Jussara identifica e discute as razões que promovem o ocultamento das mulheres como agentes da história da economia solidária. Decisões recentemente efeti- 
vadas e documentadas no contexto institucional brasileiro da economia solidária permitem à autora acrescentar elementos factuais contextualizados à elaboração de uma pauta orientadora para que a economia solidária reconheça algumas das reivindicações feministas, concernentes sobretudo a relações de gênero, étnico-raciais e geracionais, que constituem condições imprescindíveis para a construção de uma economia efetivamente baseada em relações solidárias.

$\mathrm{O}$ artigo de Paulo Fernandes Keller analisa as potencialidades do cooperativismo no contexto das transformações contemporâneas do trabalho artesanal partindo de um estudo de caso realizado na Cooperativa das Artesãs dos Lençóis Maranhenses (Artecoop), situada no município de Barreirinhas (MA). O crescimento da produção, agora mais direcionada aos mercados modista ou de turismo, e o impacto de políticas governamentais com ênfase no associativismo e no empreendedorismo de tipo empresarial constituem os principais fatores relacionados por Keller às modificações recentes do trabalho artesanal no Brasil. Enfatiza-se a relação entre o trabalho cooperativado e a produção artesanal a redes de relações sociais, econômicas e institucionais. Por outro lado, evidencia-se um tipo de associativismo que, embora não incorpore essencialmente o ideal da autogestão enfatizado na economia solidária, inibe a dependência a redes de subcontratação industrial e a ação de comerciantes intermediários na cadeia de produção do artesanato.

No artigo seguinte, Lorena Poblete analisa a mudança de formas de subcontratação de mão de obra na vitivinicultura na província de Mendoza, na Argentina, em modos alternativos de autogestão da inserção ao mercado de trabalho. A pesquisadora realizou uma pesquisa qualitativa longitudinal, entrevistando trabalhadores, em épocas de colheita diferentes e obtendo uma reconstrução das trajetórias familiares e laborais que se torna muito fecunda para a análise do processo de reestruturação produtiva da agroindústria vitivinícola na região, a partir do início da década de 1990. Poblete critica as novas formas cooperadas em relação à organização do trabalho de colheita da uva realizado antes, quando a produção, quantitativamente menor e de vinhos comuns, se destinava ao mercado local. O trabalho de colheita era realizado coletivamente pela família proprietária, com a participação externa de núcleos familiares de 'contratistas', trabalhadores volantes que recebiam remuneração mensal durante dez meses por ano e porcentagem da colheita. Com a diversificação e o incremento da produção para contemplar as exigências do mercado exportador, surgiram as formas alternativas de contratação, geralmente ilegais, para aumentar o número de trabalhadores temporários sem elevar os custos laborais. Tais formas de inserção num mercado de trabalho excludente, como o uso coletivo das faturas de trabalhadores 'autônomos' individuais, emergiram, paradoxalmente, de iniciativas dos próprios trabalhadores, diante da iminência de perderem seus vínculos como contratistas. $\mathrm{O}$ intercâmbio de faturas entre trabalhadores ingressantes autônomos e trabalhadores regularizados, prática ilegal, também depende, por outro lado, de relações de confiança e da manutenção de laços parentais e de vizinhança tão enaltecidos nas redes de solidariedade. A segunda forma alternativa de contratação corresponde à constituição de falsas cooperativas, na verdade com o papel de empresas de serviços temporários que adquirem o direito de isenção de encargos laborais, de que são beneficiárias as cooperativas stricto sensu. Diante da análise de Poblete do falso cooperativismo em Mendoza, o leitor interessado pode cotejar, em alguns aspectos, o exame desse problema pelo sociólogo Jacob Lima em outros setores produtivos no Brasil (Lima, 1998, 2004).

Marina Roriz, com seu artigo Lixo, Identidade e Trabalho, encerra neste dossiê o bloco de publicações com foco principal no trabalho 
cooperado. A autora recorre a autores como Erving Goffman, Zygmunt Bauman e Ulrich Beck para analisar transformações na recuperação da autoestima e na constituição da identidade social em catadores de materiais recicláveis inscritos em quatro associações cooperativistas em Goiânia (GO). Empregando como técnicas de investigação a observação etnográfica e a realização de entrevistas em profundidade com trabalhadores e trabalhadoras, Marina analisa as estratégias construídas para atenuar a depreciação do self diante da exclusão social e obter reconhecimento a partir de experiências associativas com base em princípios da economia solidária. Destaca-se, no entanto, que o processo de constituição identitária para trabalhadores que se mantêm na ocupação de catador permanece ambivalente, apesar de implicar, certamente, algum tipo de ascensão social e valorização da autoestima e de requerer, necessariamente, uma reconstrução de atributos e qualificativos culturalmente associados a objetos a serem eliminados e pessoas 'invisíveis', responsáveis por coletarem o que deve ser transformado e, em consequência, manterem limpo o ambiente social.

$\mathrm{O}$ artigo de Ignasi Icart e Alejandro Pizzi analisa o crescimento do empreendedorismo empresarial na Espanha, abordando as diferenças entre a concepção predominante de iniciativa empresarial, marcada pelo senso de oportunidade, ideias inovadoras e liderança, e o fenômeno contemporâneo, típico da precarização das relações de trabalho assalariadas. Nesse novo empreendedorismo, surge a flexibilização da lógica liberal no lugar do contrato de trabalho fordista.

$O$ estudo que os autores realizaram baseia-se em entrevistas em profundidade e grupos de discussão nas regiões de Andaluzia, Catalunha, Valência e Múrcia. Eles encontraram um perfil social para esses empresários(as), como trabalhadores(as) nos serviços, sendo a maioria mulheres, com elevado capital cultural (formação de nível superior), entre 30 e 45 anos, casado(a) e com filhos. Em vez do modelo tradicional de empresariado, eles se depararam com a falta de emprego, os baixos salários, a precariedade, a informalidade e a feminização tanto do setor de serviços quanto desse empreendedorismo. $\mathrm{O}$ trabalho flexível, de tempo parcial, estratificado segundo as relações sociais de gênero, realizado a partir das novas tecnologias e do acesso à internet, como autoemprego que requer baixo investimento ajusta-se ao modelo globalizado de gestão das empresas, reduzindo os custos de suas transações.

Os autores indicam como se formou "um novo paradigma de organização do tecido empresarial que supôs diluir em grande medida os estatutos de emprego, começando pelo profissional e dissolver os limites organizacionais de tal maneira que as identidades de empregador, empregado e trabalhador 'autêntico' foram substituídas progressivamente por meras estruturas de gestão da força de trabalho e por várias formas de trabalho precário" (Icart; Pizzi, 2011).

O trabalho precário também foi tema de reflexão no artigo de Isabel Georges sobre os(as) agentes comunitários(as) de saúde em uma etnografia realizada na Cidade Tiradentes, periferia na área metropolitana de São Paulo. A autora mostra a atuação do Estado na precarização do emprego, no trabalho em cuidados, exercido nessa região particularmente por mulheres negras, bastante enraizadas na localidade estudada, atuando como mediadoras entre o Estado e a população, negociando o serviço a ser prestado aos usuários. Segundo ela, a posição de agente comunitário(a) de saúde é transpassada por múltiplas ambiguidades, inclusive a de ser agente e usuária dos serviços. A posição encontra-se imbricada entre a flexibilização das relações de trabalho e as lutas por redemocratização das relações do Estado com os movimentos de saúde, revelando outra situação ambígua. 
Trata-se de um serviço público no qual predomina a perspectiva privatista na região, com a transferência das responsabilidades do Estado para Organizações Sociais, acompanhada da perda de controle social sobre esses programas de saúde. É uma atividade que exige o Ensino Médio completo e remunera $\mathrm{R} \$ 600,00$, valor bem abaixo do que é pago para as demais ocupações da saúde que atuam nos postos de atendimento. Embora as condições de trabalho sejam nomeadas por Georges como uma "atividade constrangida", mantendo as agentes em condições de dependência, ela mostra como tal emprego trouxe melhoria na autonomia econômica, social e sexual dessas mulheres.

A autora mostra também como as mediações e negociações que as agentes comunitárias de saúde precisam realizar para executar o trabalho e se legitimar na localidade não envolvem apenas o Estado e os usuários. Elas transitam pelas instâncias de regulação existentes no território, como é o caso do poder dos traficantes, e assim "realizam um trabalho de tradução dessas diversas lógicas paralelas" (Georges, 2011).

O trabalho doméstico e as estratégias associativistas ou regulacionistas para abrandar a precarização no setor constituem o tema em dois artigos. Ana Tizianni analisa as transformações recentes no contexto do setor ocupacional doméstico na Argentina, destacando o papel da regulação estatal no sentido de promover o ingresso à formalidade e incentivar a filiação sindical. Programas governamentais que implementaram recursos para facilitar o acesso à previdência social e à aposentadoria por trabalhadoras e trabalhadores do setor foram desenvolvidos, inclusive com casos de participação ativa de sindicatos de domésticas. Os programas empregaram estratégias relativamente simples, como simplificar a inscrição a fornecer incentivos econômicos, como a possibilidade de deduzir os gastos com remuneração de empregados do imposto de renda. No entanto, Tizianni alerta que esse tipo de regulação também pode desencorajar, direta ou indiretamente, a afiliação sindical no caso de trabalhadoras domésticas. Um fato que explica a possibilidade desse efeito indesejado é que, de forma similar ao que ocorre no Brasil e em outros países da América Latina, a regulamentação da ocupação de empregada doméstica é excluída ou considerada um caso à parte na legislação trabalhista. A ambiguidade na regulamentação e a permanência de situações como a residência na casa dos patrões/empregadores, que facilitam a manutenção de relações e formas de negociação ou acordo pessoal com o empregador, são fatores que dificultam a constituição de uma categoria laboral homogênea.

Janaína Jordão, em mais um dos artigos que concernem ao serviço doméstico, traz outros elementos para compreender os entraves ao associativismo sindical, à institucionalização e até mesmo ao reconhecimento subjetivo por parte das trabalhadoras de uma categoria ocupacional de empregada doméstica. Ainda que se reconheça a efetiva contribuição do associativismo no setor para a melhoria das relações salariais e laborais das trabalhadoras domésticas, uma análise histórica e sociológica da formação social brasileira revela a força de uma hibridação que relaciona os laços escravistas às interações no ambiente dos serviços domésticos. A subalternidade e a afetividade, atributos que aproximavam a casa grande da senzala, contrapostos à impessoalidade e racionalidade que requerem as relações de serviços institucionais ou em vias de profissionalização, reverberam do espaço doméstico a representações sociais e produções culturais, como no cinema e na teledramaturgia. A análise de Janaína tem o respaldo empírico de entrevistas com 31 trabalhadoras domésticas em Goiânia para analisar suas percepções sobre o serviço doméstico e relacioná-las a representações exibidas na mídia cultural.

O artigo de Gabriela Wyczykier, Acción Gremial de Base y Precariedad del Trabajo en la Industria Argentina, parte de uma caracteri- 
zação do fenômeno da precarização do trabalho, abarcando modalidades 'atípicas' distintas, quais sejam: o vínculo informal (não registrado), o emprego em tempo parcial, o emprego assalariado fraudulento e as modalidades de subcontratação e terceirização por parte de instituições ou empresas. Diante da expansão, no regime de acumulação flexível, do desemprego e das formas de trabalho precarizado e seus efeitos desagregadores no associativismo sindical, a autora elege, para uma análise de ações sindicais contra a precarização, quatro estudos de caso na Argentina, a saber: as empresas Tenaris-Siat y Siderar-Morón do setor metalúrgico e as empresas Kraft Food Argentina e Pepsico da indústria alimentícia. Ainda que seja uma característica geral do mundo do trabalho contemporâneo a convivência, no mesmo ambiente laboral, de trajetórias profissionais e de regimes de vinculação diversificados, as demandas por condições de trabalho adequadas, incluindo as condições contratuais que não reproduzam os mecanismos de exploração do capital sobre o trabalho, unificam as ações sindicais na Argentina e no contexto mais amplo internacional. A investigação comprova o papel negativo que as contratações eventuais e a rotatividade nos postos de trabalho desempenham na consolidação da identidade laboral e na consolidação de laços no ambiente de trabalho e da representatividade sindical. Embora ocorram ações de enfrentamento e de reflexão sobre a convivência de formas diferentes de vinculação na mesma unidade de trabalho, isso tem se verificado apenas em alguns setores industriais e particularmente em alguns sindicatos, sem maiores repercussões em nível associativo mais amplo. Esta lacuna na representação sindical abre caminho a uma defesa relativizada dos direitos trabalhistas, confinados em contratações esporádicas ou terceirizações. Permanece entre os delegados e sindicalistas mais ativos na Argentina a preocupação sobre como estimular os vínculos de solidariedade entre efetivos, contratados e terceirizados, para reconstruir os direitos cindidos pela flexibilização das relações contratuais.

Os demais artigos focalizam profissões de Nível Superior e seus pontos de contato com as ocupações vistas anteriormente, seja pela preocupação com o trabalho precário e pela feminização da atividade, seja pelas relações entre essas profissões e o Estado.

Maria Rosa Lombardi focaliza uma organização de trabalho associado exitosa entre 11 arquitetos e uma cientista social, todos jovens, que formaram um empreendimento autogestionário atuando em habitação popular. O grupo partilha uma visão de mundo que valoriza relações democráticas, participativas e igualitárias articuladas a uma militância profissional e política. A autora parte desse ideário e verifica as práticas identificando as contradições que elas geram, a baixa remuneração e a irregularidade que demanda trabalhos concomitantes, as dificuldades para obter recursos, a gestão que requer pressões por eficiência e especialização de funções. A pesquisa observou características da informalidade e do trabalho precário, mas a satisfação pessoal e profissional era alta. As relações sociais de sexo e divisão sexual do trabalho técnico entre arquitetos e arquiteta compõem o quadro com elas assumindo mais as tarefas rotineiras. Os embates de gênero marcavam as relações com os peões, mestres de obras e participantes dos mutirões com as arquitetas, tendo dificuldades de obter respeito e reconhecimento do saber que dominam.

Para a autora, apesar das dificuldades, "a USINA pode ser considerada uma experiência bem sucedida de trabalho associado com forte embasamento político-ideológico entre profissionais qualificados" (Lombardi, 2011).Fabio Almeida aborda as fronteiras entre profissionalismo e política, por meio da análise das relações dos médicos paulistas e o segundo governo de Adhemar de Barros (1947-1951), seja focalizando as ações da Associação Paulista de Medicina, seja pela criação da 
Secretaria de Saúde Pública e a interiorização das estruturas estaduais de saúde. O ideário do profissionalismo enfatiza seu apartidarismo e a neutralidade da expertise. $\mathrm{O}$ autor identifica características dessa lógica na medicina paulista do período, com os médicos realizando um trabalho especializado, com uma base teórica de caráter discricionário, uma jurisdição exclusiva, relativa autonomia técnica e uma ideologia de prestar um bom serviço em vez de priorizar a eficiência econômica. Indica, entretanto, como o processo de profissionalização em curso não havia consolidado as fronteiras entre profissão e política.

Esse cenário mostra que "os médicos estiveram em condições de manter uma relação de interlocução com as estruturas estatais adhemaristas" (Almeida, 2011). Tal perspectiva introduz originalidade às abordagens sobre os segmentos médios e suas relações com os governos populistas, revelando a capacidade de mobilização coletiva dos médicos e sua coesão interna para lidar com a política adhemarista, não se restringindo ao modelo típico das relações entre o populismo e as classes sociais.

Lerisson Nascimento propicia ao leitor outra contribuição ao debate dos processos de profissionalização e o impacto das relações com o Estado ao focalizar a discussão sobre a obrigatoriedade do diploma de jornalismo. $\mathrm{O}$ autor enquadra essa luta no espaço político-jurídico, no caso o Judiciário, que recebeu uma ação civil pública impetrada contra a obrigatoriedade aprovada no contexto que precedeu a Constituição de 1988. Três decisões são tomadas em instâncias distintas do Judiciário ao longo de dez anos, quais sejam: na primeira instância, a decisão é contrária à obrigatoriedade; no recurso à segunda instância, a decisão é favorável; e, no julgamento no STF, é definida a posição vetando a exigência do diploma.

Se no caso dos médicos paulistas as ambiguidades da relação com o governo adhemarista contribuíram para o avanço do processo de profissionalização, no caso em tela o resultado constrange a reserva de mercado que a Federação e o Sindicato dos Jornalistas haviam se empenhado em viabilizar.

Sintetizando a proposta analítica de Nascimento, ele procura "contribuir com o debate sobre o jornalismo no Brasil mostrando como este tem sido objeto de disputas que envolvem aspectos legais, cognitivos e identitários no espaço jurídico, mudando o foco das diversas análises sobre o jornalismo no Brasil".

O último trabalho de nosso dossiê é um estudo de Maria Natália Silveira sobre a interseção entre profissionalismo e gênero na carreira das delegadas de polícia civil. A escolha da autora para estudar esse grupo profissional decorre do ingresso feminino intensificado pela criação das Delegacias de Defesa da Mulher, em uma profissão marcada pela imagem pública de força, uso de arma e virilidade. Sua indagação gira em torno do que o ingresso de mulheres numa carreira masculina representa tanto para elas quanto para o exercício profissional. Silveira encontrou uma concentração de mulheres nas DDMs representando um enclave generificado e uma subalternização das funções desenvolvidas ali, percebidas pelos pares como assistência social. Para as delegadas, a segmentação por gênero dessas delegacias, considerada uma conquista do movimento social no combate à violência contra as mulheres, atravanca a carreira, bloqueando a ascensão às posições superiores. $\mathrm{O}$ artigo mostra que a forma de as delegadas lutarem contra isso leva ao apagamento das marcas de gênero quando este desqualifica sua expertise, mas quando ser mulher é um diferencial valorizado, essas profissionais recorrem ao feminino, gerando uma essencialização positiva. $\mathrm{O}$ estudo baseou-se em 12 entrevistas com 9 delegadas e 3 delegados da cidade de São Paulo, além dos dados quantitativos sobre a profissão. 
Para ela, a carreira apresenta um dilema: "Nesse jogo articulado, de um lado, temos a essencialização positiva, e do outro o apagamento de gênero negativo, que acabam por fragilizar as profissionais envolvidas“ (Silveira, 2011).

O conjunto dos artigos do dossiê reflete as mudanças que vêm ocorrendo no mundo do trabalho ocupacional e profissional e as contribuições dos autores na análise desses fenômenos. A precarização do trabalho mostrou-se presente em várias atividades, fosse de forma sutil, como no trabalho associado, cooperado ou no empreendedorismo, fosse nas manifestações evidentes desse processo. Nas formas de trabalho precário, vários artigos registraram a feminização da atividade, que também foi abordada na análise associativa e identitária. Não só o mercado e a globalização da economia foram vistos como promotores da flexibilização das relações contratuais, indicou-se a participação do Estado e até dos trabalhadores nas ambiguidades que envolvem tais mudanças.

Entre os grupos profissionais, o dossiê analisou fenômenos semelhantes, combinando perspectivas sócio-históricas e contemporâneas sobre o associativismo, as relações com o Estado, a profissão e a política, suas fronteiras e formas como se interpenetram. Nas carreiras de Nível Superior, as contribuições a este volume também observam o processo de feminização e o trabalho precário, que não se restringe às ocupações subalternas, se distribuindo na estrutura ocupacional no Brasil, na Argentina e na Espanha.

\section{Referências}

ALMEIDA, Fábio de Oliveira. Bases analítico-conceituais das relações de aproximação-distanciamento entre médicos e adhemarismo. Sociedade e Cultura, Goiânia, v. 14, n. 1, p. 131-140, 2011.

GEORGES, Isabel. Entre participação e controle: os agentes comunitários de saúde da região metropolitana de São Paulo. Sociedade e Cultura, Goiânia, v. 14, n. 1, p. 73-85, 2011.

ICART, Ignasi Brunet; PIZZI, Alejandro. Creación de empresas en los nuevos tiempos del trabajo asalariado. Sociedade e Cultura, Goiânia, v. 14, n. 1, p. 63-72, 2011.

LIMA, Jacob Carlos. Cooperativas de produção industrial: autonomia e subordinação. In: CASTRO, Nadya A.; DEDECCA, Cláudio S. A ocupação na América Latina: tempos mais duros. São Paulo/Rio de Janeiro, Alast, 1998.

LIMA, Jacob Carlos. O trabalho autogestionário em cooperativas de produção: o paradigma revisitado. Revista Brasileira de Ciências Sociais, São Paulo, v. 56, p. 45-74, 2004.

LOMBARDI, Maria Rosa. Trabalho associado, autogestão e arquitetura popular: uma experiência exitosa. Sociedade e Cultura, Goiânia, v. 14, n. 1, p. 121-130, 2011.

NASCIMENTO, Lerisson C. Um diploma em disputa: a obrigatoriedade do diploma em jornalismo no Brasil. Sociedade e Cultura, Goiânia, v. 14, n. 1, p. 141-150, 2011.

SCOTT, Joan Wallach. A mulher trabalhadora. In: FRAISSE, Geneviève; PERROT, Michèle. História das mulheres. O século XIX. Porto: Afrontamento, São Paulo: EBRADIL, 1991.

SILVEIRA, Maria Natália. Delegadas de polícia: profissionalismo e gênero. Sociedade e Cultura, Goiânia, v. 14, n. 1, p. 151-162, 2011. 